UDC: 615-057.875:37.091.33-027.22-028.77

DOI: 10.33320/maced.pharm.bull.2020.66.03.044

\title{
The Pharmacy simulation game- a unique global tool in pharmacy education
}

\author{
Tanja Fens ${ }^{1,2}$, Claudia Dantuma ${ }^{1}$, Katja Taxis ${ }^{1}$ \\ ${ }^{I}$ Groningen Research Institute of Pharmacy, University of Groningen, Groningen, The Netherlands \\ ${ }^{2}$ Department of Health Sciences, University of Groningen, University Medical Center Groningen, \\ Groningen, The Netherlands
}

\section{The need of effective educational concept for pharmaceutical practice}

Pharmacists are recognized as key health professionals contributing to the health of citizens by providing professional advice on the safe, effective and rational use of medicines. Often, pharmacists are the first and the last contact patients have with the health system. To fulfill this role, pharmacy students need high quality education. In recent years, concept like simulation and serious gaming are increasingly used in the education of healthcare professionals (Cain and Piascik, 2015). Gradually, such concept is introduced in pharmacy education.

\section{The Pharmacy Game in Groningen - GIMMICS $®$}

GIMMICS ${ }^{\circledR}$ is an educational game, based on gaming theory and simulation, in which teams of students run a pharmacy for a period of a few weeks (Werf et al., 2004).

In Groningen, we teach our pharmacy students a number of competencies based on the Canadian Medical Education Directives for Specialists (CanMEDs). Since 2006, this competency framework is used in the educational programs of all Dutch medical specialists. The seven roles of the Dutch community pharmacist based on the CanMEDs model are: pharmaceutical expert, communicator, collaborator, manager, health advocate, scholar and professional (Westein et al., 2019).

The game is played in a simulated environment where students are managing their own pharmacy. Each pharmacy includes a counter, dispensing facilities and pharmacy information systems. Students have to counsel patients, process prescriptions, and communicate with other health care professionals. Patients are played by actors, voluntary staff members or externals. Furthermore, students have to perform tasks such as negotiations with insurance or wholesale companies, management of legal issues with drugs of dependence, drug-use-evaluations and submission of adverse drug reactions reports (Werf et al., 2004).

\section{The Pharmacy Game internationalization}

The game was developed in 2000, at the University of Groningen in the Netherlands. Until now, it has been adopted by six other Universities: University of Utrecht, Netherlands (2004), Vrije Universiteit Brussel, Belgium (2007), University of Nottingham, UK (2015), Griffith University, Australia (2016), University of Bath, UK (2018), and Vilnius University, Lithuania (2019) (More info is available at: www.gimmics.nl).

This is unique and possibly the only example of a pharmacy game which is taught in so many different universities. This internationalization

\footnotetext{
*t.fens@ @rug.nl
} 
allows to share experiences between universities and working together towards better training of future pharmacists or other health workers.

\section{Evidence for using a simulation game in pharmacy education}

Educational gaming is a competitive activity engaging a set of rules which need to be followed. It allows active learning experience in a fun way advocating active participation and problem solving. Participants are able to train skills of independent decision making, learn from experience and peer communication, and develop a goal-oriented attitude (Akl et al., 2013). Evidence has also shown that simulation games enhance student's communication skills. Furthermore, simulation in education allows real-life experience. Moreover, the students gain memorable learning, practical skills, and use experience to handle new situations and improve their performance. At the same time, it represents a safe learning environment within a controlled setting (Hasan et al., 2017; Pasquale, 2015).

Yet, in practice the use of games in medical practice remains dependent on evidence about the quality of its effectiveness and requires validation before implementation (Gorbanev et al., 2018).

The pharmacy simulation game GIMMICS ${ }^{\circledR}$ is practiced with success for 20 years now, focusing on the setting of community pharmacy. We have shown that it can be adapted to different health care contexts across the globe. It also allows to teach a wide range of different competences ranging from leadership, interprofessional collaboration to clinical competences. The concept could be also used to train other healthcare workers requiring practical experience e.g. family medicine (Van Rossem et al., 2019). Student evaluations indicate a preference for gaming teaching/learning methods compared to traditional teaching methods (Cain and Piascik, 2015; Eukel et al., 2017).

In conclusion, the Pharmacy simulation game represents a unique global tool for pharmacy education.

\section{References}

Akl, E.A., Sackett, K.M., Erdley, W.S., Mustafa, R.A., Fiander, M., Gabriel, C., Schünemann, H., 2013. Educational games for health professionals. Cochrane Database of Systematic Reviews. Available at: https://doi.org/10.1002/14651858.CD006411.pub3.

Cain, J., Piascik, P., 2015. Are serious games a good strategy for pharmacy education?. Am. J. Pharm. Educ. 79(4). Available at: https://doi.org/10.5688/ajpe79447.

Eukel, H.N., Frenzel, J.E., Cernusca, D., 2017. Educational gaming for pharmacy students - design and evaluation of a Diabetes-themed escape room. Am. J. Pharm. Educ. 81(7). Available at: https://doi.org/10.5688/ajpe8176265.

Gorbanev, I., Agudelo-Londoño, S., González, R.A., Cortes, A., Pomares, A., Delgadillo, V., Yepes, F.J., Muñoz, Ó., 2018. A systematic review of serious games in medical education: quality of evidence and pedagogical strategy. Med. Educ. Online 23(1). Available at:

https://doi.org/10.1080/10872981.2018.1438718.

Hasan, S., Tarazi, H.M.K., Halim Hilal, D.A., 2017. Enhancing student communication skills through Arabic language competency and simulated patient assessments. Am. J. Pharm. Educ. 81(4). Available at: https://doi.org/10.5688/ajpe81476.

Pasquale, S.J., 2015. Educational science meets simulation. Best Practice \& Research Clinical Anaesthesiology, Simulation in Anaesthesia and Surgery 29, 5-12. Available at: https://doi.org/10.1016/j.bpa.2015.02.003.

Van Rossem, I., Devroey, D., De Paepe, K., Puttemans, F., Petit, P., Schol, S., Deridder, S., Vandevoorde, J., 2019. A training game for students considering family medicine: an educational project report. J. Med. Life 12, 411-418.

Werf, J.J. van der, Dekends-Konter, J., Brouwers, J.R.B.J., 2004. A new model for teaching pharmaceutical care services management. Pharmacy Education 4(3-4), 165-169.

Westein, M.P.D., de Vries, H., Floor, A., Koster, A.S., Buurma, H., 2019. Development of a postgraduate community pharmacist specialization program using CanMEDS competencies, and entrustable professional activities. Am. J. Pharm. Educ. 83(6). Available at: https://doi.org/10.5688/ajpe6863. 